\title{
Pensar a partir "de baixo": o simbolismo de Marielle Franco para a transformação teórica das Relações Internacionais
}

\author{
Thinking "From Below": the Symbolism of Marielle Franco to the theoretical transformation of \\ International Relations
}

DOI: https://doi.org/10.22456/2178-8839. 113886

Mariana Felix Quadros Universidade Federal do Rio Grande do Sul, Porto Alegre, Brasil marianafelixdequadros@gmail.com

Jocieli Decol Universidade Federal de Santa Catarina, Florianópolis, Brasil jocidecolo8@gmail.com

Maria Eduarda Piacentini Universidade Federal de Santa Catarina, Florianópolis, Brasil piacentinime@gmail.com

\section{Resumo}

O presente artigo busca discutir como o simbolismo de Marielle Franco pode contribuir para a transformação teórica das Relações Internacionais (RIs). Para isso, faremos uma reflexão sobre a trajetória política de Marielle Franco, uma mulher negra, LGBTQIA+, socióloga, vereadora e militante feminista antirracista, associando a sua figura ao debate teórico e político de Relações Internacionais, por meio dos conceitos de raça e gênero. A pergunta que guia esta pesquisa é: como a figura de Marielle Franco se relaciona à transformação teórica das RIs? Para responder tal questionamento, será realizada uma pesquisa qualitativa de caráter exploratório, orientada por teorias críticas das Relações Internacionais. Nosso argumento cen tral é que o simbolismo de Marielle Franco representa a urgência em pluralizar e transformar a disciplina, conectando teoria e política e descentralizando o seu foco de análise centrado no Estado para a incorporação de atores múltiplos e de perspectivas outras, que pensam o internacional a partir "de baixo". Deste modo, relacionar Marielle às RIs nos guia para uma nova visão de mundo, na qual a agência de corpos historicamente marginalizados e silenciados é incorporad a à realidade internacional.

Palavras-chave: Marielle Franco; Teoria de Relações Internacionais; Raça; Gênero;

\begin{abstract}
This article aims to discuss how Marielle Franco's symbolism can contribute to the theoretical transformation of International Relations (IR). Therefore, we will reflect on the political trajectory of Marielle Franco, a black woman, LGBTQIA+, sociologist, city councilor, and anti-racist feminist activist, associating her figure to the theoretical and political debate on International Relations through the concepts of race and gender. The question that guides this research is: how does the figure of Marielle Franco relate to the theoretical transformation of IR? To answer this, qualitative and exploratory research will be conducted, guided by critical theories of International Relations. Our central argument is that the symbolism of Marielle Franco represents the urgency to pluralize and transform the discipline, connecting theory and politics and decentralizing its state-centered analytical focus to the incorporation of multiple actors and other perspectives that think the international "from below". In this way, relating Marielle to IR guides us towards a new worldview, in which the agency of historically marginalized and silenced bodies is incorporated into the international reality.
\end{abstract}

Keywords: Marielle Franco; International Relations Theory; Race; Gender; 


\section{Introdução}

Marielle Francisco da Silva, mais conhecida como Marielle Franco, foi uma intelectual e vereadora na cidade do Rio de Janeiro (2017-2018). Mulher negra, LGBTQIA+, socialista e engajada às lutas feminista e antirracista, foi assassinada por simbolizar a esperança e a radicalidade em meio à manutenção do status quo e das desigualdades que hierarquizam os corpos na sociedade. Treze tiros foram disparados contra o seu carro para silenciá -la, entretanto, comoo Instituto Marielle Franco menciona, "quem mandou matar Marielle mal podia imaginar que ela era semente, e que milhões de Marielles em todo mundo se levantariam no dia seguinte” (INSTITUTO MARIELLE FRANCO, 2020).

Não é de hoje que as feministas negras enfatizam o quanto mulheres negras empoderadas incomodam as forças hegemônicas, sobretudo patriarcais, misóginas e masculinas (HOOKS, 2019; KILOMBA, 2019;DAVIS, 2016). Esteincômodo possui como estratégia o silêncio. Deste modo, se nas Relações Internacionais o silenciamento em torno da raça e do gênero é uma forma de poder e de manter o status quo, o assassinato de Marielle, em 2018, na cidade do Rio de Janeiro, seguiu a mesma lógica. Pois, como enfatiza Grada Kilomba (2019), o racismo além de discursivo, tambémbusca controlar corpos.

A partir desse panorama, o presente artigo busca discutir como o simbolismo de Marielle Franco pode contribuir para a transformação teórica das Relações Internacionais. Nosso argumento central é que Marielle Franco não apenas reforça a insuficiência das teorias mainstream para pensar a realidade das Relações Internacionais contemporâneas, mas, ao mesmo tempo, rompe com a visão tradicional de ativismos políticos das mulheres na respectiva área. Neste sentido, Marielle, enquanto símbolo, lança luz à relevância das mulheres negras na (re)construção teórica e política das Relações Internacionais, propondo olhares distintos e contra-hegemônicos que emergem de suas contribuições enquanto intelectuale militante política.

Centralizar a figura de Marielle Franco para compreender as dinâmicas da disciplina se contrapõe às teorias mainstream das Relações Internacionais, comprometidas com o fortalecimento de uma ontologia e epistemologia hegemônicas, que desconsideram os sujeitos sociais e os seus corpos como atores relevantes e impactantes no espaço internacional. Neste sentido, o simbolismo de Marielle, juntamente às lentes de análise das teorias críticas, sobretudo as que se constituem a partir dos debates de raça e de gênero, trazem novos olhares à compreensão das RIs.

Sendo assim, para além de contribuir para a construção de ontologias e epistemologias outras, o símbolo de Marielle fortalece lutas e impulsiona movimentos por justiça social e igualdade ao redor do globo, uma vez que o "simbolismo ocorre em qualquer política, incluindo a política internacional, e faz parte das relações internacionais como um todo” (FAIZULLAEV, 2013, p. 92). Portanto, símbolos como: bandeiras, hino nacional, figuras políticas e/ou religiosas “estão realmente presentes em todas as esferas da vida” (GILL; ANGOSTO-FERRANDEZ, 2018, p. 429), influenciando na mobilização de identidades coletivas e processos de identificação, os quais são responsáveis por organizar dinâmicas e ações políticas que transformem a realidade social tanto no âmbito doméstico quanto no cenário internacional. Desta forma, o Instituto Marielle Franco ${ }^{1}$, coordenado pela sua família, tem sido uma importante ferramenta de articulação e de representatividade em prol de seu legado junto aos organismos internacionais, de forma que o símbolo político e intelectual que Marielle se tornou, principalmente no âmbito das resistências políticas, atue encorajando mulheres a seguirem na luta por direitos humanos e, consequentemente, trazendo impactos na esfera internacional.

Iniciativas como: i) o mural artístico e político em Berlim, idealizado pela artista russa Katerina Voronina com o apoio da organização Anistia Internacional (AI) e do Museu Urban Nation, com o objetivo de chamar a atenção para a necessidade de proteção a ativistas de direitos humanos (MADE FOR MINDS, 2021); ii) a homenagem à Marielle na marcha do Dia Internacional da Mulher em Berlim, no ano de 2019 (MADE FOR MINDS, 2021); iii) a placa “Rio de Janeiro”, em uma estação de metrô em Buenos Aires, onde, por meio de um código QR visitantes poderão conhecer um pouco mais da história

\footnotetext{
O Instituto Marielle Franco é uma organização sem fins lucrativos, criada pela familia de Marielle, com a missão de inspirar, conectar e potencializ ar mulheres negras, LGBTQIA+ e periféricas a seguirem movendo as estruturas da sociedade por um mundo mais justo e igualitário.
} 
de Marielle (G1,2021a); iv) o jardim Marielle Franco, na Gare de l'Est, em Paris, articulado pela RED.Br, uma rede europeia em defesa da democracia (G1, 2021b); v) a homenagem à vereadora no $33^{\circ}$ Lovers Film Festival, a mostra de cinema LGBTQIA+ mais antiga da Europa, realizada na Itália; e vi) a obra de André de Castro, em exposição nos Estados Unidos, onde Marielle está lado a lado com Martin Luther King (PUTTI, 2019), materializam os ideais defendidos e vivenciados pela vereadora, conjugando lutas no âmbito internacional e desafiando as análises mainstream das RIs, centralizadas em questões de estados do Norte global e que deixam à mercê a agência de corpos marginalizados, suas narrativas e o seu potencial de transformação.

Logo, a partir dessas problemáticas, será realizada uma pesquisa qualitativa de caráter exploratório, orientada por teorias críticas das Relações Internacionais, com base nas reflexões sobre raça e gênero. Cabe mencionar a dificuldade em encontrar materiais que versem sobre o tema no campo das Relações Internacionais, sobretudo referente à figura de Marielle Franco, seja tanto pela atualidade de alguns dos acontecimentos retratados quanto pela (falta de) reconhecimento frente aos debates aqui levantados. Destarte, o trabalho se debruçanão a penas na literatura produzida pela disciplina, mas rememora leituras de áreas correlatas, como a Sociologia e a Ciência Política.

Em termos de organização, o artigo está estruturado em três seções. A primeira, “Eu sou porquenós somos: Marielle Franco e a sua trajetória política”, abordará a trajetória política de Marielle e a sua transformação em um símbolo de luta e resistência na esfera internacional. Já na segunda seção, intitulada “O pessoal é internacional: raça e gênero nas RIs”, será analisado como podemos conectar o simbolismo de Marielle Franco à reflexão teórica e política das RIs, a partir das categorias de raça e gênero. E, por fim, na terceira seção, “(Des)construindo o mainstream: as Relações Internacionais a partir de baixo", argumentaremos a insuficiência das teorias mainstream das Relações Internacionais para analisar a realidade do sistema internacional, posto que elas não dão destaque à agência de grupos marginalizados e de conceitos fundamentais como raça e gênero.

\section{“Eu sou porque nós somos": Marielle Franco e a sua trajetória política}

“Entre os becos e vielas da favela, sobreviver é a nossa maior resistência” (FRANCO, 2016, s.p.). Marielles, Beneditas, Talírias, e outras mulheres negrasque ocupam/ocuparam espaços públicos e políticos no Brasil fazem parte de um projeto de resistência frente à lógica política hegemônica demarcada pelo machismo, racismo e desigualdade de classe, e que se consolida por meio de uma sociedade heteronormativa (TEIXEIRA; ZAMORA, 2019), na qual as mulheres são restringidas ao silêncio e a condições pré-estabelecidas, que variam de acordo com a sua raça, sexualidade e posicionamento social. Neste cenário, mulheres negras, historicamente excluídas e inferiorizadas, enfrentam enormes dificuldades para alcançar espaços institucionais de representação social, política e cultural.

Ao olhar para a figura de Marielle Franco e as suas pluralidades, percebe-se o atravessamento das opressões que fortificam esse sistema sexista, racista e classista (TEIXEIRA; ZAMORA, 2019), da do que a vida das mulheres, sobretudo negras, está colocada em uma posição na qual elas, além de serem coletivamente marginalizadas nas dinâmicas do trabalho, são empurradas a uma condição social de inferioridade em comparação aos outros grupos (CAPORAL; L IMA, 2018). Sendo assim, as lutas de Marielle articulam demandas históricas, políticas e culturais que se contrapõem às circunstâncias delimitadas pela dominação Ocidental eurocêntrica, a qual se baseia na racialização e subjugação de corpos (WERNECK, 2009).

Consequentemente, o seu ativismo sem fragmentações expressa a possibilidade dos/das sujeitos/as se colocarem de forma integral no mundo, mesmo em contextos de vulnerabilidades múltiplas (TEIXEIRA;ZAMORA, 2019). Deste modo, "a luta das mulheres negras contra a opressão de gênero e de raça vem desenhandonovos contornos para a ação política feminista e anti-racista" (CARNEIRO, 2011, s.p.), uma vez que a sua movimentação se dá no sentido de erguer os seus pares ao mesmo tempo em que alçam voo (DAVIS, 2016). Destarte, mulheres como Marielle trazem em seu corpo elementos necessários para que a política seja um instrumento de emancipação feminina e uma busca pela justiça social 
(GUIMARÃES-SILVA, 2018; CAPORAL; LIMA, 2018), reafirmando a importância e o potencial de transformação dos movimentos sociais pensados por mulheresfeministas.

“Mulher, negra, mãe, da favela” (FRANCO, 2016, s.p.): com essas palavras Marielle Franco se apresenta em seu vídeo de campanha à vereança da cidade do Rio de Janeiro, em 2016. “Cria” da favela da Maré, na zona Norte do Rio de Janeiro, socióloga e mestra em Administração Pública, Marielle foi eleita vereadora da Câmara do Rio de Janeiro pelo PartidoSocialismo e Liberdade (PSOL). Em seu “currículo” também está o trabalho em organiza ções sociais, como Redes da Maré e Brazil Foundation, e, posteriormente, a atuação como assessora parlamentar do Deputado Marcelo Freixo (PSOLRJ), ocasião na qual ajudou na coordenação da Comissão de Defesa dos Direitos Humanos e Cidadania da Assembleia Legislativa do Rio de Janeiro (ALERJ) (RAMOS, 2019).

Aos dezenove anos, tornou-se mãe de uma menina, condição que a influenciou a defender o direito das mulheres e o feminismo na periferia. Após perder uma amiga em um confronto entre policiais e traficantes, Marielle passou a militar pela defesa dos direitos humanos, denunciando casos de violência policial contra pessoas negras e da favela (RAMOS, 2019; CAPORAL; LIMA, 2018). Superando diversos entraves, tornou -se "uma exceção à regra comum à realidade das favelas, em que o acesso ao Ensino Superior é praticamentevedado em virtude da precariedade do ensino básico e de imperativos mais prementes" (RAMOS, 2019, p.13).

Como resultado, "surge o sujeito político coletivo Marielle Franco para representar toda a população historicamente excluída da política na luta pela concretização dos direitos humanos e fundamentais” (CAPORAL; LIMA, 2018, p. 3). Deste modo, a sua candidatura representa o desejo de colorir o espaço legislativo e se colocar como representante de vozes silenciadas, subvertendo a lógica política e social pautada por hierarquias e privilégios que colocam o pensamento branco, masculino e eurocêntrico em posição de destaque (CAPORAL; LIMA, 2018).

Ao ocupar uma cadeira no legislativo, Marielle deixou nítida a sua luta pelo reconhecimento das identidades das favelas (GUIMARÃES-SILVA, 2018). Em seus projetos de lei, o fio condutor era a valorização de vidas negras e a proteção aos direitos das mulheres. Neste contexto, ações contra a atuação arbitrária da polícia militar e em combate ao assédio em transportes públicos, bem como a criação de casas de parto públicas e de creches noturnas, deram forma ao mandato da vereadora e delinearam algumas de suas áreas de enfrentamento. Em 2018, Mariellefoi convidada a a ssumir a relatoria da Comissão de Direitos Humanos da Câmara de Vereadores do Rio de Janeiro, responsável por acompanhar a intervenção militar na segurança pública do estado (GUIMARÃES-SILVA, 2018).

Na Comissão, Marielle trabalhou junto à investigação de casos de violência policial, prestando apoio jurídico e psicológico às famílias vitimadas e cobrando respostas dos órgãos judiciários. Na sua atuação, a vereadora sempre deixava expresso o seu posicionamento de que as populações periféricas e racializadas seriam as principais afetadas em uma conjuntura de crescente militarização e de valorização de uns em detrimento de outros. Assim, Marielle pautava a organização coletiva e a construção de um projeto cultural contra-hegemônico (PEREIRA; RIOS, 2019), que fosse capaz de rediscutir temas essenciais e fundantes da sociedade brasileira. Como contribuição, Marielle apresentou em sua dissertação de mestrado, “UPP: a redução da favela a três letras”, um olhar diferente à segurança pública, colaborando para o debate acerca da (des)militarização policial e jogando luz à importância da participação da sociedade civil nos debates de segurança pública (FRANCO, 2014).

Em 14 de março de 2018, Marielle e seu motorista Anderson Gomes foram assassinados a tiros, após a participação da vereadora no evento “Jovens negras movendo estruturas”, na cidade do Rio de Janeiro. O atentado serviu como ponto de partida para que outras mulheres e movimentos sociais revolucionários se colocassem enquanto resistência elutassem por uma vida mais justa e digna. Mesmo que a atuação da vereadora fosse local, a repercussão de sua execução se tornou assunto internacional (GUIMARÃES-SILVA, 2018), de modo que "manifestações ocorreram no mundo todo e Marielle foi homenageada por diversas escolas, universidades, prefeituras [e] coletivos culturais” (ROCHA, 2018, p. 279). 
Na visão de Rocha (2018, p. 278), "Marielle foi executada comoforma de silenciá-la e de parar sua luta, em defesa dos direitos dos moradores de favela, mulheres, negros e negras, LGBTs, ou seja, da classe trabalhadora tão explorada e violentada". Portanto, a potência do seu legado é fruto das lutas contra "sexismo, racismo, homofobia e transfobia, desigualdade econômica, criminalização da pobreza e diferentes formas do neocolonialismo” (DI EUGENIO, 2020, p. 284). Enquanto símbolo, Marielle conecta as lutas por um mundo mais igualitário, alimentando movimentos feministas nacionais e transnacionais que se contrapõem à visão feminista branca e ocidental, reprodutora de lógicas de dependência e subordinação. Assim, “falar de Marielle é sair do neutro e colocar-se aolado de suas causas, por sua memória e contra seu apagamento" (PASSOS, 2020, p. 92).

Por tudo o que representa, Marielle se tornou tão perigosa aos poderes hegemônicos. Como desta ca Talíria Petrone (2019, p. 21), ela própria uma das sementes de Marielle, “mataram o seu corpo. O seu espírito de luta não”. Neste sentido, relembrar Marielle nos possibilita reacender a esperança e rearticular as lutas, devido à multiplicidade de significados e representações políticas que o seu corpo e o seu legado carregam. Para além disso, o simbolismo de Marielle Franco também nos permite repensar as Relações Internacionais, uma disciplina construída sobre pilares de hierarquia e opressões, onde tão pouco espaçoé destinadoàs perspectivas críticas. As reflexões sobre gêneroe raça, incorporadas por Marielle em suaslutas, contribuem para pensarmos o cenário internacional, e é a partir delas que buscaremos tensionar as Teorias de Relações Internacionais (TRIs), rumoà sua transformaçãoteórica e política.

\section{“O pessoal é internacional”: raça e gênero nas RIs}

A subrepresentação das mulheres brasileiras, sobretudo negras, nos mecanismos de discussão internacionais, na produção intelectual das RIs, ou ainda, como referências globais no feminismoé uma realidade histórica. Lélia Gonzalez, à exemplo, iniciou sua produção intelectual no mesmo período que Angela Davis, discutindo temas como interseccionalidade, mas por conta da "geopolítica do conhecimento", como diria Maldonado-Torres (2006), a primeira não recebeu o mesmo reconhecimento que a segunda. Nãoé à toa que, recentemente, em 2019, em uma vinda para o Brasil, Angela Davis proclamou quelêssemos mais Lélia Gonzalez para a compreensão da condição das mulheres negras no Brasil. Da mesma forma, esta relação desigual na produção do conhecimento se traduz no âmbito disciplinar das Relações Internacionais. Seja porque tal disciplina possui uma relação simbiótica com hierarquias ou porque a on tologia das RIs está comprometida com a realidade Ocidental. Por conta disso, mesmo quando intelectuais negros/as brasileiros/as se propõem a discutir o internacionalismo, estes/as não são incorporados/as nas grades de ensino ou nas pesquisas acadêmicas.

Para compreendermos essa hierarquização é preciso, inicialmente, discutir a estruturação do sistema internacional e as suas relações de poder. Charles Mills (1997), em “O Contrato Racial”, menciona que os estados ocidentais se reconhecem como superiores e, consequentemente, estabelecem uma relação de ajuda mútua entre si. Desta forma, o sistema internacional seria baseado em uma supremacia branca, tendo em vista que o racismo seria um sistema político e uma estrutura de poder baseado em um contrato racial - camuflado por um contrato social - muito bem aceito, inclusive, pelas teorias tradicionais de RIs, nas quais os membros da raça dominante formariam um acordovelado para garantir para si a maior parte dos benefícios econômicos. Levando isto em consideração, autores/as como Chowdhry e Nair (2002) e Henderson (2017) acusam as teorias mainstream de racistas, uma vez que elas se constroem dentro de um sistema político dedicado à supremacia branca.

Portanto, o silenciamento ou silêncio em relação às hierarquias é um fenômeno de poder na respectiva na área. Ou como chama Karine Silva (2021) “a surdez e a cegueira seletivas para as dinâmicas raciais nas Relações Internacionais”. Por sua vez, a própria hierarquização do espaçointernacional em linhas raciais é um fenômeno de poder.É neste sentido que Du Bois (1925) defendia que o problema do séculoXXI continua sendo a linha de cor, uma vez que a relação entre povos 
e pessoas de pele clara e de pele escura são um reflexo das relações sociais externas e internas: tensões que envolvem riqueza e pobreza, a violência, conflitos internos e desigualdades sociais. À vista disso, a raça é um marcador que organiza as hierarquias estabelecidas no moderno sistema internacional e também nas relações sociais. Embora para muitos acadêmicos, especialmente homens brancos, analisar raça, etnia e gênero seja uma tarefa fácil, tais categorias são extremamente complexas. Isso porque são categorias que estão sempre sujeitas às alterações, tendo seu sentido sempre dependente a um determinado contexto ou a uma determinada estrutura socioeconômica. Assim, com base nos trabalhos de Paul Gilroy (1987) e Stuart Hall (1992), nota-se uma complexidade nas análises de raça e etnia, tendo em vista que alguns grupos étnicos são vítimas de uma linha divisória permanente, e outros, de certa forma, são aceitos pelos grupos dominantes.

Além disso, novos processos estratégicos da política racial adotados em alguns países, como Guatemala e Brasil, a partir da coalizão dos grupos étnicos na formação de uma identidade coletiva comum, têm efeitos conceituais (HANCHARD, 2001). Conceitualmente, podemos definir raça como "uma ponte entre sentidos e práticas socialmente construídas, entre as interpretações subjetivas e a realidade materialvivida” (HANCHARD, 2001, p. 28), ou, segundo Gilroy (1987), raça seria uma categoria política aberta, pois é por meio de sua luta que poderá ser definida qual concepção irá permanecer e quais serão as condições que ela se manterá ou desaparecerá. Em termos de hierarquias no espaço internacional, a raça tem sido um elemento fundamental na própria criação do sistema mundial moderno, nas suas representações e explicações, moldando visões e práticas da política internacional, além de contribuir para uma ordem global profundamenteinjusta (PERSAUD; WALKER, 2001).

Se por um lado a raça é importante e fundamental no campo teórico, por outro, o gênero também. Teóricas feministas há tempos denunciam que o "pessoal é político”, e como disse Cynthia Enloe (2014), o pessoal é também internacional. A importância de categorias como gênero, raça, classe, sexualidades, etc., para a análise das RIs é evidente, mas, as raízes predominantemente eurocêntricas, racistas e masculinas da disciplina, por muito tempo, direcionaram os estudos e teorias da área para questões que não consideravam grupos de fora desse padrão, como as mulheres, negros/as, indígenas, pessoas trans, entre outras diversidades, e que são, sim, peças -chave na organização e funcionamento do cenário internacional. Por que, então, seria “menos teórico" estudá-los ou incorporá-los às análises de Relações Internacionais? Esse é um questionamento recorrente das teorias feministas das RIs e de abordagens não-hegemônicas da disciplina.

Ann Tickner (1997), umas das principais teóricas do feminismo nas Relações Internacionais chama atenção para a relutância das teorias malestream ${ }^{2}$ da disciplina em dialogar com as perspectivas feministas. Segundo a autora, ocorre um “estranhamento generificado” nessa relação, em que as TRIs mainstream “simplesmente não conseguem entender” oque as feministas estão falando/escrevendo/teorizando. Isso ocorre, de acordo com Tickner (1997), pois há uma diferença de posicionamento epistemológico entre ambos os grupos teóricos. Posto isso, no diálogo entre fe ministas e teóricos/as tradicionais ocorrem vários mal entendidos, como, por exemplo, a noção de gênero ser associada apenas ao aspecto pessoal. A partir disso, questiona -se se as feministas estão fazendo teoria afinal de contas, umavez que não trabalham com objetos e temáticas tidas como centrais dentro das abordagens hegemônicas da disciplina. Tickner, por sua vez, demonstra como o gênero, para além de abarcar o aspecto individual, também se constitui como elemento central na própria formação do sistema internacional, o qual se organiza por meio da desigualdade de gênero e outros sistemas de opressão.

Levando isso em consideração, o gênero não diz respeito apenas às mulheres, mas à própria organização do poder na sociedade. Nesse sentido, diferentemente das teorias mainstream, que têm na figura do Estado (unitário, associal e masculino) seu objeto epistêmico fundamental, as teorias feministas de RI propõem uma abordagem centrada na análise

\footnotetext{
2 "Malestream" é um conceito frequentemente utilizado por teóricas feministas para se referir às produções científicas realizadas exclusivamente a partir da realidade de homens, que veem a si próprios como representações do universal. Essa perspectiva exclui outras experiências e pontos de vista, reforçando a desigualdade de gênero.
} 
das relações sociais, por meio da qual, procuram compreender as dinâmicas globais da opressão de gênero e também transformar a ordem internacional na qual vivemos, queé socialmente construída com base em relações de poder desiguais (TICKNER,1997). Deste modo, as teorias feministas de RI se apresentam não apenas como um a reflexão teórica, mas como “uma intervenção política” na própria disciplina (SOUZA, 2018, p. 430).

A tarefa das teorias feministas de RI é, portanto, desconstrutiva e reconstrutiva. Isso pois, precisam, ao mesmo tempo, reinterpretar conceitos centrais às teorias mainstream e desenvolver novas reflexões quelevem em consideração as dinâmicas de gênero, promovendo, assim, um novo olhar para a realidade internacional. Nesse processo, as feministas destacam como as estruturas constitutivas do Estado e do mercado são profundamente generificadas, como a economia e a política internacional, que focam no homem/masculino - ignorando outras realidades - e, deste modo, demonstram como a não inclusão da categoria de gênero enfraquece as análises de RI (YOUNGS, 2004).

Ao expandirem as fronteiras da própria disciplina, as teorias feministas aprofundam o entendimento das relações internacionais incorporando análises que focam na relação entre dinâmicas de nível micro e macro, analisando como o pessoal reflete no internacional e também como instituições e estruturas internacionais impactam grupos sociais e indivíduos. Nesse sentido, as teorias feministas de RI questionam as bases epistêmicas tradicionais e incorporam uma abordagem "de baixo para cima", na qual se preocupam em compreender as dinâmicas globais a partir da realidade de grupos marginalizados, como as mulheres. As TRIs malestream, no entanto, utilizam abordagens "de cima para baixo", direcionando a atenção principalmente às grandes estruturas de poder e suas interações (TICKNER, 2001).

À medida em que as teorias feministas tensionaram as disciplinas acadêmicas, os feminismos passaram por processos de transformação e reordenamento. A noção do conceito "mulher" entendido de forma universal, baseado na imagem de uma mulher branca, Ocidental, hétero e de classe alta, escancarava a perpetuação de opressões e silenciamentos dentro do feminismo hegemônico. Assim, com o intuito de diversificar e ampliar ofeminismo, mulheres do Sul global, periféricas, negras, LGBTQIA+, camponesas, entre outras, passaram a questionar essa "mulher universal”, a partir da qual o feminismo hegemônico se constrói, ressaltando que vivemos distintas realidades, somos múltiplas e precisamos abarcar essas pluralidades dentro do movimento e de suas teorias. Por meio deste questionamento, o feminismo negro, pós-moderno, decolonial, lésbico, otransfeminismo, etc.,vêm transformando o movimento, ressal tando as distintas opressões que as mulheresperiféricas vivenciam. Nesse processo, podemos associar a figura de Marielle Franco à multiplicidade de vozes e realidades que transformam ofeminismo.

O feminismo negro, uma das grandes pautas de Marielle, tem trazido contribuições teóricas e práticas ao desenvolvimento do feminismo em seus diversos âmbitos. Essa perspectiva tem como ponto de partida a experiência de mulheres negras e a sua centralidade na conformação das relações sociais. Além disso, também enfatiza a importância de pensarmos as opressões de maneira interseccional, atentando para a conexão e não a separação entre os sujeitos e suas lutas (COLLINS, 2019). As características da epistemologia feminista negra, apresentadas por Patricia Hill Collins, são refletidas na vida e obra de Marielle Franco, e, por isso, sua figura representa um guia de reflexão e transformação teórica e política das Relações Internacionais.

\section{(Des)construindo o mainstream: as Relações Internacionais a partir de baixo}

Embora argumentemos sobre a importância das categorias de raça e gênero para a compreensão das Relações Internacionais, as realidades ontológica e epistemológica continuam as menosprezando. Logo, analisar as RIs a partir "de baixo", significa não se pautar pela forma com que os debates mainstream estão dados na área. À vista disso, sustentamos que não é agregativo realizar a crítica ontológica e epistêmica e, ao mesmo tempo, reforçar autores/as, visões de mundo e narrativas centradas no Norte global, que se colocam enquantoliteraturas e histórias únicas das Relações Internacionais, em detrimento das demais perspectivase saberes. O ponto, em si, não é somente a incorporação de temas marginalizados. 
Mais que isso, propomos problematizar e repensar os pressupostos racistas, eurocêntricos e machistas que silenciam outras formas de conhecimento e visões de mundo nas RIs.

Levando isso em consideração, é importante repensar o início da disciplina de Relações Internacionais como parte deste olhar contra-hegemônico. Nascida no início do século XX, o seu objetivo era cumprir compromissos e pautas euroestadunidenses que se orientavam, inclusive, pelo acirramento de teorias racistas na academia. Didaticamente, as RIs são delineadas a partir de duas narrativas, as quais se conectam à construção de hierarquias como raça e gênero (SILVA, 2021). A primeira, concebe a disciplina em termos cronológicos, ao passo que, a segunda, organiza a área de estudo ideologicamente por correntes teóricas, sob “grandes debates” (SMITH, 2000). Ao trabalhar com base nos debates entre: i) Realismo versus Idealismo; ii) Realismo versus Behaviorismo; iii) Realismo versus Liberalismo versus Marxismo (interparadigmático); e iv) Positivismo versus Pós-positivismo, a ideia central era oxigenar as reflexões e perspectivas teóricas em torno de qual seria a realidade do sistema internacional e como esta deveria ser estudada.

O problema acerca destas abordagens é a falta de representação histórica desenhada pela disciplina (SMITH, 2000). Pensar com base em uma linha do tempo ou grandes eventos cria “mitos” acerca da fundação das Relações Internacionais, cerceando a riqueza das experiências e focalizando a construção teórica da área à interpretação Ocidental do sistema internacional e das suas dinâmicas (ASHWORTH, 2014). Partir de uma história mítica e única seria o que a escritora nigeriana Chimamanda Ngozi Adichie (2009) atrela à ideia de "princípio nkali”, uma expressão igbo para "ser maior que o outro", a qual representa o poder de despossuir por meio da criação de narrativas, superficializar vivências e estereotipar. Consequentemente, ambas as abordagens partem deste princípio e adotam certas concepções como universais, tornando-as acontecimentos definitivos, ao mesmo tempo em que carregam discursos que podem ser utilizados para promover algumas formas de pensamento, enquanto silenciam outras (ASHWORTH, 2014; SILVA, 2021).

Neste sentido, as teorias mainstream de Relações Internacionais são criadas para servir a uma ideia e justificar preferências e formulações políticas (COX, 1981) que, ao pensar a política internacional de forma objetiva, positivista e universalista, buscam celebrar, defender e promover o Ocidente (HOBSON, 2012; ACHARYA, 2011). Por conseguinte, embora essas teorias associem a institucionalização do estudo das RIs à Primeira Guerra Mundial (1914-1918) e aos esforços pela paz e segurança internacionais, elas estavam associadas, sobretudo, ao colonialismo, à escravidão e à partilha do continente africano, sendo responsáveis por legitimar o discurso de que "cabia ao homem branco o fardo de civilizar os povos atrasados” (SILVA, 2021, p. 40) e que fez da Conferência de Berlim (1884-1885) o marco da exploração neocolonialista das potências europeias em África (DU BOIS, 1925; SILVA, 2021).

Destarte, não existe uma neutralidade ou ingenuidade na idealização da disciplina, mas uma exclusão/omissão de outros territórios e cosmologias que fazem com que toda a construção das RIs seja feita de forma a afirmar a história da Europa enquanto história do mundo (ACHARYA, 2011; JONES, 2006), ao passo que empreende o sistema vestfaliano de organização política e social, colocando “dissidentes” às margens do sistema internacional (ACHARYA; BUZAN, 2007) e marcando o descompromisso em relação à análise e problematização das desigualdades perpetradas pelo continente europeu no âmbitointernacional.

À vista disso, teorias e abordagens alternativas - formuladas fora do eixo epistemológico Europa-Estados Unidos - que estão preocupadas com outros saberes e realidades para além dos debates acerca das motivações para a guerra/paz ou sobre a centralidade do Estado no sistemainternacional, são escondidas pelo discurso hegemônico a partir de barreiras linguística ou de classificação de área (ACHARYA; BUZAN, 2007), sendo rotul adas de irrelevantes dentro da disciplina (“isto não é Relações Internacionais”), dado que não se tornam convincentes do ponto de vista ontológico e epistemológico (SMITH, 2000). Assim, “a parte subalternalizada [...] não é reconhecida como sujeito político nem epistêmico” (SILVA, 2021, p. 38), restando apenas a posição de “objetos de pesquisa passíveis de classificação, de escrutínio, de primitivização” (SILVA, 2021, p. 43). 
Partindo destas problemáticas, entender o exercício de poder representado pelo mainstream teórico das RIs - o qual não reconhece as categorias de raça e de gênero -, resulta em uma análise limitada, dado que não são consideradas experiências mais amplas, nem as complexidades e estruturas que sedimentam o internacional. Em contraposição às correntes mainstream, propomos centralizar a experiência de mulheres negras, sobretudo de Marielle Franco, para compreender as dinâmicas e disputas internacionais, dado que é essencial ter em mente a conexão entre teoria e prática e a perspectiva de transformação que advém do entrelaçamento de ambas (SELIS, 2014). Portanto, o símbolo de Marielle fomenta a construção do pensamento crítico acerca da realidade em que vivemos e potencializa as lutas por transformação social. Incorporar essa reflexão ao debate teórico e político das Relações Internacionais é urgente e provoca a (re)construção da própria disciplina.

Também, é importante considerar que a opressão não se finda em termos de autores/as e narrativas, uma vez que permanece relacionada a princípios da própria organização social, que se reafirmam por meio de certas visões de mundo. Thomas Tieku (2011), neste sentido, denuncia os valores liberais e individuais, pelos os quais as Relações Internacionais estão comprometidas. O autor enfatiza que o escopo universal é baseado nas assimilações europeias do mundo mediante à modernidade (mundialização das crenças ocidentais), fortalecendo a opressão cultural, tanto do Sul global quanto das não-elites do Norte. Através de sua análise sobre as sociedades coletivistas da África, Tieku (2011) aponta que as histórias locais são severamente afetadas pelos processos de colonização, pois a organização social das diversas regiões do continente africano se afastava da concepção individual e autointeressada do homem branco europeu, na qual imperam interesses racionais, vinculados às esferas do “eu” ao invés do “nós” (TIEKU, 2011).

Somando-se às narrativas críticas, "Repensando as Relações Internacionais”, de Fred Halliday (1994), demonstra que, embora as RIs não focalizem na discussão das "revoluções" , elas são importantes para demarcar momentos de rupturas e fusões, sendo possível associá-las ao papel desempenhado pelos movimentos sociais encabeçado por mulheres, pela população negra e por demais grupos subalternizados. O movimento sufragista, o movimento por direitos civis nos Estados Unidos, as lutas indígenas na América Latina, o papel das mulheres negras contra o apartheid e o movimento negro no Brasil pela criação de ações afirmativas são alguns exemplos de mobilizações sociais que influenciaram significativamente à transformação política e conjuntural dos Estados. Sendo assim, por quais razões as mulheres negras não são agentes da respectiva área?

Ao se limitar ao estudo da realidade Ocidental, a academia busca a manutenção do status quo da disciplina, a qual, mesmo sendo cada vez mais oxigenada ainda é, majoritariamente, constituída por homens brancos, vinculados a centros de pesquisa acadêmica no Norte global e que, na maioria das vezes, partem da centralidade do Esta do, inferiorizando a capacidade de agência de outros atores no sistema internacional. Neste contexto, proposições vinculadas aos "grandes debates” persistem enquantolente analítica e sãopredominantes na análise política e teórica das Relações Internacion ais. Sendo assim, olhar criticamente para a construção da disciplina significa expor os silêncios camuflados pelos “mitos” (ASHWORTH, 2014). Para isso, é preciso romper com a concepção difundida nos estudos mainstream das Relações Internacionais, nos quais autores/as reforçam certos tipos de realidades e difundem que a disciplina parte do comprometimento com a paz mundial, tendo a Sociedade das Nações (SdN) e, posteriormente, a Organização das Nações Unidas (ONU), como centro de ações humanitárias globais. Levando isto em consideração, Olivia Rutazibwa (2020), traz o Genocídio de Ruanda (1994) como exemplo para apontar que livros didáticos mainstream não correspondem, necessariamente, a realidade. A autora demonstra que o seu “[...] interesse por RI veio do fato de que não conseguia entender como a ONU - que, de acordo com os livros de RI, era um farol de esperança e salvaçãoliderado pelo Ocidente e o berço dos direitos humanos - deixou um milhão de pessoas morrer em 1994” (RUTAZIBWA, 2020, s.p.,traduçãonossa),

\footnotetext{
3 Halliday (1994) defende as revoluções como categoria de análise nas Relações Internacionais, uma vez que elas são pontos de transição e de formação sem os quais o mundo moderno não seria como é. Assim, é através da relação revolução-Estado que há processos de derrubada dos Estados existente s e consolidação de novos.
} 
sendo completamente omissa aos trágicos desdobramentos que ocorreram no território ruandês após o assassinato de dez paraquedistasbelgas na véspera dogenocídio.

Trazendo a sua experiência, a autora discute o teórico, defendendo que as RIs devem abandonar a noção de ajuda e enfrentar o racismo e sistemas de opressão com seriedade por meio de reparações e não apenas de forma retórica. Neste sentido, “[..] toda a noção de ajuda é obscena - e racista. As relações internacionais que não reproduzem a lógica do colonialismo devem, ao invés disso, envolver-se com ideias de reparação, dignidade e até recuo" (RUTAZIBWA, 2020, s.p., traduçãonossa). Assim, dar visibilidade às narrativas subalternas-pensando a partir “de baixo” -, dispensar mitos ainda difundidos nos centros de estudo e valorizar perspectivas de resistência, significa criar reparações teóricas e práticas no interior da disciplina (RUTAZIBWA, 2020; SILVA, 2021). Da mesmaforma que, aos poucos, vem-se promovendo reparações com políticas raciais e de gênero, as Relações Internacionais precisam se reinventar e, por meio de uma agenda antirracista e antimachista empírica e teórica, “atacar as variárveis que desempoderam e marginalizam” (SILVA, 2021, p. 49, grifo da autora). Pensar a importância dos símbolos, em especial da figura de Marielle Franco, é um passo importante para o fortalecimento de uma agenda comprometida com a mudança epistêmica e ontológica das Relações Internacionais.

\section{Considerações finais}

Esta pesquisa teve como objetivo averiguar de que maneira o simbolismo de Marielle Franco se relaciona com a transformação teórica das Relações Internacionais. Sendo assim, na primeira seção, demonstramos como o as sassinato de Marielle ecoou pelo globo, causando indignação e impulsionando a construção de uma solidariedade internacional em defesa dos direitos humanos. Este movimento, pautado na figura da vereadora, reflete a potencialidade de seu simbolismo na conexão entre diversaslutas e centraliza a agência de movimentos sociais e outros atores nas dinâmicasinternacionais. Posto isso, relacionar o simbolismo de Marielle às Relações Internacionais implica repensar teórica e politicamente atores não-estatais e, particularmente, corpos marginalizados e oprimidos na esfera internacional.

Neste sentido, compreendemos que símbolos influenciam nas percepções da realidade, transformando ideias complexas em representações mais acessíveis que criam contornos acerca de como percebemos o mundoe entendemos as suas dinâmicas. Quando nos referirmos ao simbolismo de Marielle Franco, apontamos para as camadas de significado que a sua figura política impulsiona em ações ao redor do globo, fazendo, assim, florescer novas solidaried ades transnacionais. A partir disso, a sua figura, ao representar a centralidade dos corpos marginalizados na formação/transformação da realidade internacional e ressaltar a conexão desses corpos com as dinâmicas de raça e gênero, aponta para a urgência na transformaçãoteórica das Relações Internacionais.

Desta percepção, parte o debate levantado na seção dois, o qual reforça a necessidade da incorporação de categorias de raça e gênero nas Relações Internacionais, fazendo com que a disciplina seja capaz de capturar a concretude das dinâmicas que envolvem as relações de poder, majoritariamente assentadas na constante marginalização da realidade não-ocidental, não-masculina, não-branca e não-estatal.Com base nisso, entendemos que “o pessoal”, representado pelas trajetórias de Marielle, é político e internacional, de modo que a sua figura pode ser trazida às RIs como símbolo da conexão entre as diversas lutas sociopolíticas, impulsionando as abordagens teóricas contra-hegemônicas, que descentralizam o olhar da disciplina e chamam atenção para atores internacionais outros. Marielle Franco não reforça apenas a insuficiência das teorias do mainstream para pensar a realidade internacional, como também rompe com a visão tradicional de ativismos políticos na respectiva área, ressaltando o potencial das mulheres negras periféricas.

Por fim, na terceira seção, problematizamos a construção da disciplina de Relações Internacionais e como isso se conecta às fragilidades das TRIs mainstream, ressaltando a necessidade de pluralizá-las. Levando isso em consideração, o simbolismo de Marielle Franco guia as RIs em direção a um olhar mais sensível às dinâmicas raciais, de gênero e de classe, evidenciando a agência de atores outros no cenário internacional e invertendo a lógica "de cima para baixo”, segundo a qual se desenvolvem tanto a política internacional quanto às teorias mainstream das RIs. Partindo disso, direcionamos o 
nosso olhar para os corpos oprimidos pelas hierarquias internacionais e reconhecemos a sua presença e caráter transformador, marcando um posicionamento político pela equidade de gênero, pelo fim do racismo e das múltiplas formas de opressão, ao mesmo tempo em que caminhamos contra a lógica hegemônica de construção do conhecimento. Construir teoria em Relações Internacionais com base na experiência de Marielle Franco significa reivindicar a pluralização de perspectivas, corpos e subjetividades nos espaços políticos e acadêmicos, impulsionando um olhar transdisciplinar que esteja atento às dinâmicas de opressão na relação pessoal-internacional.

\section{Referências}

ADICHIE, Chimamanda Ngozi. O perigo de uma história única. Oxford, 2009. Disponível em: https://www.ted.com/talks/chimamanda_ngozi_adichie_the_danger_of_a_single_story?language=pt-br. Acesso em: 20 jul.2021.

ACHARYA, Amitav. Dialogue and Discovery: In Search of International Relations Theories Beyond the West. Millennium: Journal of International Studies, v. 36, n. 3, p. 619-637, 2011. Disponível em: https://journals.sagepub.com/doi/10.1177/0305829811406574. Acesso em: 17 jul. 2021.

ACHARYA, Amitav; BUZAN, Barry. Why is there no non-Western international relations theory? An introduction. International Relations of the Asia-Pacific, v. 7, n. 3, p. 287-312, 2007. Disponível em: https://academic.oup.com/irap/articleabstract/7/3/287/749880?redirectedFrom=fulltext. Acesso em: 17 jul. 2021.

ASHWORTH, Lucian. A History of International Thought: From the origins of the modern state to academic International Relations. Londres: Routledge, 2014.

CAPORAL, Angélica Azeredo Garcia; LIMA, Fernanda da Silva. Direitos humanos e feminismo negro: Marielle presente. In: Seminário Nacional - Demandas sociais e políticas públicas na sociedade contemporânea, 14 ed. Anais. Santa Cruz do Sul: EDUNISC, 2018. Disponível em: https://online.unisc.br/acadnet/anais/index.php/snpp/article/view/17962/1192611931. Acesso em: 8 mai. 2021.

CARNEIRO, Sueli. Enegrecer o Feminismo: a situação da mulher negra na América Latina a partir de uma perspectiva de gênero. Portal Geledés, 2011. Disponível em: https://www.geledes.org.br/enegrecer-o-feminismo-situacao-da-mulher-negra-na-america-latinapartir-de-uma-perspectiva-de-genero. Acesso em: 8 mai. 2021.

CHOWDHRY, Geeta; NAIR, Sheila. Introduction: Power in a postcolonial world: race, gender, and class in International Relations. In: CHOWDHRY, Geeta; NAIR, Sheila. Power, Postcolonialism and International Relations: reading race, gender and class. Londres: Routledge, 2002, p.1-32.

COLLINS, Patricia Hill. Epistemologia Feminista Negra. In: COLLINS, Patricia Hill. Pensamento feminista negro: conhecimento, consciência e a política do empoderamento. São Paulo: Boitempo, 2019, p. 401-432.

COX, Robert W. Social forces, states and world orders: beyond international relations theory. Millennium: Journal of International Studies, v. 10, n. 2, p. 126-155, 1981. Disponível em: http://pos-graduacao.uepb.edu.br/ppgri/files/2016/02/Cox-Robert-Social-ForcesStates-and-World-Orders_Beyond-International-Relations-Theory.pdf. Acesso em: 17 jul. 2021.

DAVIS, Angela. Mulheres, raça e classe. 1. ed. São Paulo: Boitempo, 2016.

DI EUGENIO, Alessia. Marielle Franco fiorisce in tutti noi: um olhar italiano sobre a herança das lutas de Marielle Franco (e muitas outras). Cadernos de Gênero e Diversidade, Salvador, v. 6, n. 2, p. 284-294, 2020. Disponível em: https://periodicos.ufba.br/index.php/cadgendiv/article/view/35005/23123. Acesso em: 8 mai. 2021.

DU BOIS, William Edward. Worlds of Color. Foreign Affairs, 1925. Disponível em: https://www.foreignaffairs.com/articles/africa/1925 04-01/worlds-color. Acesso em: 28 abr. 2021.

ENLOE, Cynthia. Bananas, Beaches and Bases: Making Feminist Sense of International Politics. Berkeley: University of California Press, 2014.

FAIZULLAEV, Alisher. Diplomacy and symbolism. The Hague Journal of Diplomacy, v. 8, n. 2, p. 91-114, 2013. Disponível em: https://www.deepdyve.com/lp/brill/diplomacy-and-symbolism-3KOyeRgjJE. Acesso em: 12 jul. 2021.

FRANCO, Marielle. UPP - A redução da favela a três letras: uma análise da política de segurança pública do estado do Rio de Janeiro. 2014. 136 f. Dissertação (Mestrado) - Programa de Pós-Graduação em Administração, Universidade Federal Fluminense (UFF), Niterói, 2014. Disponível em: https://app.uff.br/riuff/bitstream/1/2166/1/Marielle\%20Franco.pdf. Acesso em: 8 mai. 2021.

FRANCO, Marielle. Quem é Marielle Franco? Rio de Janeiro, 2016. Disponível em: https://www.youtube.com/watch?v=DPs2o7VgwJA\&ab_channel=MarielleFranco. Acesso em: 8 mai. 2021.

G1 (GRUPO GLOBO). Metrô de Buenos Aires inaugura placa em homenagem a Marielle Franco. G1 Grupo Globo. São Paulo, 14 mar. 2021a. Disponível em: https://g1.globo.com/mundo/noticia/2021/03/14/metro-de-buenos-aires-inaugura-placa-em-homenagem-amarielle-franco.html. Acesso em: 28 abr. 2021. 
G1 (GRUPO GLOBO). Jardim em homenagem a Marielle Franco é inaugurado em Paris. G1 Grupo Globo. São Paulo, 21 set. $2021 b$. Disponível em: https://g1.globo.com/mundo/noticia/2019/09/21/jardim-em-homenagem-a-marielle-franco-e-inaugurado-emparis.html. Acesso em: 28 abr. 2021.

GILL, Graeme;ANGOSTO-FERRANDEZ, Luis F. Introduction: Symbolism and Politics. Politics, Religion \& Ideology, v. 19, n. 4, p. 429 433, 2018. Disponível em: https://www.tandfonline.com/doi/full/10.1080/21567689.2018.1539436. Acesso em: 12 jul. 2021.

GILROY, Paul. There Ain't No Black in the Union Jack. Londres: Hutchinson, 1987.

GUIMARÃES-SILVA, Pâmela. Marielle e a representatividade da vida que carrega o signo da morte. In: MARQUES, Ângela Cristina Salgueiro (org.). Vulnerabilidades, justiça e resistências nas interações comunicativas. Belo Horizonte: PPGCOM-UFMG, 2018. p. 60-70. Disponível em:https://www.academia.edu/37711911/Marielle_e_a_representatividade_da_vida_que_carrega_o_signo_da_morte. Acesso em: 8 mai. 2021.

HALL, Stuart. Race, culture and communications: looking backward and forward at Cultural Studies. Rethinking Marxism, v. 5, n. 1, p. $10-18,1992$.

HALLIDAY, Fred. Repensando as Relações Internacionais. 2. ed. Porto Alegre:Editora da UFRGS, 2007.

HANCHARD, Michael. Orfeu e o Poder: O movimento negro no Rio de Janeiro e São Paulo. 1. ed. Rio de Janeiro: EDUERJ, 2001.

HENDERSON, Errol A. Racism in International Relations Theory. In: ANIEVAS, Alexander; MANCHANDA, Nivi; SHILLIAM, Robbie (org.). Race and Racism in International Relations. Londres: University College, 2017. p. 32-231.

HOBSON, John M. The Eurocentric Conception of World Politics: Western International Theory, 1760 -2010. Cambridge: Cambridge University Press, 2012.

HOOKS, Bell. E eu não sou uma mulher? 1. ed. Rio de Janeiro: Rosa dos Tempos, 2019.

INSTITUTO MARIELLE FRANCO. Quem é Marielle Franco? Instituto Marielle Franco. Rio de Janeiro. 2020. Disponível em: https://www.institutomariellefranco.org/quem-e-marielle. Acesso em: 28 abr. 2021.

JONES, Branwen G. Introduction: International Relations, Eurocentrism, and Imperialism. In: JONES, Branwen G. (ed.). Decolonizing International Relations. Lanham: Rowman \& Littlefield,2006,p.1-19.

KILOMBA, Grada. Memórias da plantação. Episódios de Racismo Cotidiano. 1. ed. Rio de Janeiro: Gráfica Stamppa, 2019.

MADE FOR MINDS. Berlim inaugura mural em homenagem a Marielle Franco. Made for Minds. 08 mar. 2021. Disponível em: https://www.dw.com/pt-br/berlim-inaugura-mural-em-homenagem-a-marielle-franco/a-56809871. Acesso em 28 abr. 2021.

MALDONADO-TORRES, Nelson. La topología del ser y la geopolítica del saber. Modernidad, imperio, colonialidad. In: MIGNOLO, Walter; SCHIWY, Freya; MALDONADO-TORRES, Nelson (org.). Des-colonialidad del ser y del saber: (videos indígenas y los límites coloniales de la izquierda) en Bolivia. Buenos Aires: Del Signo, 2006.p. 63-130.

MILLS, Charles W. The Racial Contract. Nova Iorque: Cornell University Press, 1997.

PASSOS, Lara de Paula. Vive em mim toda Marielle Franco: repressão, resistência, arqueopoesia e a materialidade das vivências de mulheres negras. Revista do Museu de Arqueologia e Etnologia, São Paulo, v. 35, p. 79-102, 2020. Disponível em: https://www.revistas.usp.br/revmae/article/view/163772. Acesso em: 8 mai. 2021.

PEREIRA, Ana Valéria Dias; RIOS, Maria Beatriz Lugão. Rosa para as Marielles. Historiæ, Rio Grande, v. 10, n. 1, p. 121-136. 2019. Disponível em: https://periodicos.furg.br/hist/article /view/10994. Acesso em: 8 mai. 2021.

PETRONE, Talíria. Prefácio à edição brasileira. In: ARRUZZA, Cinzia; BHATTACHARYA, Tithi; FRASER, Nancy. Feminismo para os 99\%: Um manifesto. São Paulo: Boitempo, 2019, p. 11-22.

PERSAUD, Randolph B.; WALKER, Rob. B. J. Apertura: Race in International Relations. Alternatives: Global, Local, Political, v. 26, n. 4, p. 373-376, 2001. Disponível em: https://journals.sagepub.com/doi/abs/10.1177/030437540102600401. Acesso em: 28 abr. 2021.

PUTTI, Alexandre. A semente virou árvore: 1 ano após morte, Marielle é símbolo mundial. Carta Capital. São Paulo, 14 mar. 2019. Disponível em: https://www.cartacapital.com.br/sociedade/a-semente-virou-arvore-1-ano-apos-morte-marielle-e-simbolo-mundial. Acesso em: 28 abr. 2021.

RAMOS, Guilherme Antunes. As violações de direitos humanos e o silenciamento de parlamentares no Brasil contemporâneo: os casos de Marielle Franco e Jean Wyllys. In: Congresso Latino-Americano de Ciência Política da Associação Latino-Americana de Ciências Políticas (ALACIP), 10 ed. Anais. Monterrey, 2019. Disponível em: https://alacip.org/cong19/163 - antunes-19.pdf. Acesso em: 8 mai. 2021.

RUTAZIWBA, Olivia. Why is mainstream International Relations blind to racism? Foreign Policy, 2020. Disponível em: https://foreignpolicy.com/2020/07/03/why-is-mainstream-international-relations-ir-blind-to-racism-colonialism. Acesso em: 20 jul. 2021. 
ROCHA, Lia de Mattos. A vida e as lutas de Marielle Franco. Revista em Pauta: Teoria social e realidade contemporânea, Rio de Janeiro, v. 16, n. 42, p. 274-280,2018. Disponível em: https://www.e-publicacoes.uerj.br/index.php/revistaempauta/article/view/39439. Acesso em: 8 mai. 2021.

SELIS, Lara. A dialética da anarquia: sobre a teoria neorrealista de Kenneth Waltz. Carta Internacional, Belo Horizonte, v. 9, n. 1, p. 105120, 2014. Disponível em: https://cartainternacional.abri.org.br/Carta/article/view/97. Acesso em: 10 mai. 2021.

SILVA, Karine de Souza. "Esse silêncio todo me atordoa": a surdez e a cegueira seletivas para as dinâmicas raciais nas Relações Internacionais. Revista de Informação Legislativa: RIL, Brasília, v. 58, n. 229, p. 37-55, 2021. Disponível em: https://www12.senado.leg.br/ril/edicoes/58/229/ril_v58_n229_p37.pdf. Acesso em:20.jul.2021.

SMITH, Steve. The discipline of international relations: still an American social science? British Journal of Politics and International Relations, v. 2, n. 3, p. 374-702,2000. Disponível em: https://journals.sagepub.com/doi/10.1111/1467-856X.00042. Acesso em: 20 jul. 2021.

SOUZA, Natália Maria Félix de. Introduction: Gender in the Global South: Disturbing International Boundaries. Contexto Internacional, v. 40, n. 3, p. 429-434, 2018. Disponível em: https://www.scielo.br/j/cint/a/Z658R3BPVHD59dxc5yLDsMd/?lang=en. Acesso em: 20 jun. 2021

TEIXEIRA, Sérgio Henrique; ZAMORA, Maria Helena. Pensando a interseccionalidade a partir da vida e morte de Marielle Franco. Dignidade Re-Vista, v. 4, n. 7, p. 139-153, 2019. Disponível em: http://periodicos.pucrio.br/index.php/dignidaderevista/article/view/938. Acesso em: 8 mai. 2021.

TIEKU, Thomas Kwasi. Collectivist Worldview: Its Challenge to International Relations. In: CORNELISSEN, Scarlett; CHERU, Fant u; SHAW, Timothy M. (ed.). Africa and International Relations in the 21st Century. Basingstoke: Palgrave Macmillan, 2011. p. 36 - 50.

TICKNER, J. Ann. You just don't understand: troubled engagements between feminists and IR theorists. International Studies Quarterly, v. 41, n. 4, p. 611-632,1997. Disponível em: https://academic.oup.com/isq/article/41/4/611/1786067. Acesso em:20 jun. 2021.

TICKNER,J.Ann. Gendering world politics: issues and approaches in the post-cold war era. Nova Iorque: Columbia University Press, 2001.

WERNECK, Jurema. Nossos passos vêm de longe! Movimentos de mulheres negras e estratégias políticas contra o sexismo e o racismo. In: VERSCHUUR, Christine (ed.). Vents d'Est, vents d'Ouest: mouvements de femmes et féminismes anticoloniaux. Genebra: Graduate Institution Publications, 2009.p. 151-163. Disponível em: https://books.openedition.org/iheid/6316. Acesso em: 10 mai. 2021.

YOUNGS, Gillian. Feminist International Relations: a contradiction in terms? Or: why women and gender are essential to unders tanding the world 'we' live in. International Affairs, v. 80, n. 1, p. 75-87, 2004. Disponível em: https://onlinelibrary.wiley.com/doi/abs/10.1111/j.1468-2346.2004.00367.x. Acesso em: 20 jun. 2021.

\begin{tabular}{ll}
\hline Funções de colaboração exercidas & \\
\hline Mariana Felix Quadros: & Escrita (primeira redação); Escrita (revisão e edição); \\
Jocieli Decol: & Escrita (primeira redação); Escrita (revisão e edição); \\
Maria Eduarda Piacentini: & Escrita (primeira redação); Escrita (revisão e edição); \\
\hline
\end{tabular}

